\title{
A oralidade na escola: seria uma solução se não fosse um problema
}

\begin{abstract}
Resumo: O presente trabalho discute o ensino de língua voltado também para a oralidade, situando essa como sendo prática social interativa que vai além da linguagem verbal, inclusive interferindo nas relações interpessoais em sala de aula, cenário privilegiado nesse artigo, na qual o silêncio no que se refere à oralidade é uma constante e o que poderia ser uma solução para problemas de interação interpessoal e de leitura, mantém-se como um problema.

Palavras-chave: Oralidade. Ensino. Linguística. Metodologia de ensino.
\end{abstract}

É sabido, através de pesquisas realizadas (FÁVERO, 2003; MUNIZ, 2007), que a expressão oral de um modo geral - e a oralidade em particular - anda desprestigiada nos planos de aula dos/das docentes da escola brasileira. E é compreensível que a nossa escola dê pouca atenção à oralidade, uma vez que essa instituição reproduz a cultura da sociedade em que se insere e a nossa, de modo geral, ignora a fala autônoma e crítica.

Em pesquisa desenvolvida no programa de pós-graduação stricto sensu da UFBA em 2007, na qual foram observadas professoras desenvolvendo aulas de língua portuguesa para alunos do primeiro ano do ensino médio, das cinco professoras observadas em vinte e cinco aulas nenhuma sequer mencionou a oralidade. (CAMPINHO, 2007) Muniz (2007, p. 33) relata que "[...] em investigação sobre a prática da expressão oral na escola, os dados indicaram que, na escola de primeiro grau de então, hoje, escola básica de ensino fundamental, a atividade de expressão oral pelos alunos foi algo inexpressivo". Essas pesquisas, realizadas em 1980 e 2005, separadas no tempo, unem-se na conclusão: o ensino de língua portuguesa na educação básica brasileira desconsidera a oralidade.

No entanto, é imperativo que essa situação sofra uma radical mudança, pois cada vez mais a sociedade, de um modo geral, e o mercado de trabalho, em particular, vêm solicitando profissionais com autonomia e inventividade, mudando o modelo tayloristafordista ${ }^{2}$ pelo modelo, digamos, multimidiático ${ }^{3}$ que vivemos hoje. Nesse modelo, o compromisso do educador não é mais formar
Rosemary Lapa Oliveira² rosy.lapa@gmail.com UFBA - FACED

(1) Doutoranda do programa de pós-graduação em Educação da Faculdade de Educação da UFBA. Mestre em Letras e Linguística pelo Instituto de Letras da UFBA. Assistente de pesquisa do Grupo de estudo da linguagem GELING da

Faculdade de Educacão da UFBA. Professora do Estado da Bahia.

(2) O modelo taylorista-fordista é essencialmente autoritário. A partir dos anos 60 começam a ser estudados modelos organizacionais participativos. Nos dias atuais o trabalhador está sendo exigido de outras formas: demandar outros esforços, tais como o esforço intelectual, além do físico, a criatividade, e participação em tomadas de decisão. Disponível em: $<$ http://bartolomeu.br.tripod.com/ htm/modelo.htm >. Acesso em: 25 jul. 2011.

(3) O mesmo que Nelson Pretto chama de "sociedade dos mass media". Esse termo é tomado como paráfrase do cunhado por Pretto (1996). 
(4) Dinâmica que visa, sobretudo, à participação ativa de todos os alunos, a fim de despertar sua criatividade, hábitos de estudo. bom relacionamento, auxiliandoos a superar suas inibições e fazendo perceber que há formas de aquisicão do conhecimento além da assistência às aulas convencionais. Sua viabilização se dá por meio do desempenho de diversas funções assumidas pelos alunos. Cadá função pode ser desempenhada por um ou mais alunos, ficando sua designação a cargo do professor, que levará em consideração o número de alunos da turma, os talentos e inclinações de cada um e a efetiva participação de todos. (prof. Dr. Neurivaldo de Guzzi Filho. da UESC) reprodutores obedientes do sistema, "[...]é, antes, com a formação do aluno, com o desenvolvimento de suas capacidades tanto de reflexão sobre a linguagem, quanto de uso crítico da língua". (RANGEL, 2007, p. 11)

Nesse cenário, a oralidade deveria entrar na escola ocupando espaço semelhante ao ocupado pela escrita, porém, mais do que isso, trazendo outro olhar que vise "a formação de um novo ser humano" (PRETTO, 1996, p. 20), o que exige "[...] uma nova escola e um novo professor, capazes de trabalhar com esse mundo de informação e de tecnologia" (PRETTO, 1996, p. 20) que vem se consolidando paulatinamente na nossa sociedade e que exige uma formação mais ampla no que concerne à linguagem, uma vez que traz, com o novo suporte, novos gêneros textuais orais e escritos.

Primeiramente, é importante deixar claro o que seja mesmo oralidade. Segundo Marcuschi (2001, p. 25), seria: "uma prática social interativa para fins comunicativos que se apresenta sob variadas formas ou gêneros textuais fundados na realidade sonora; ela vai desde uma realização mais informal à mais formal nos mais variados contextos de uso". Perseguindo essa definição, percebe-se que na escola atual pouco ou nada se faz com intuito de ou com finalidade de formar o cidadão para o uso pleno de sua oralidade, englobando-se aqui a escuta.

O que encontramos na escola atual, se muito, é a "aula participativa 4 " em que o aluno é instado a falar a sua dúvida, muito incentivado pelos livros didáticos que vêm trazendo questões como: "em sua opinião", "agora é a sua vez", "converse com os colegas e a professora". O que já é um avanço, mas ainda não é um trabalho que englobe a oralidade como descrita acima por Marcuschi (2001).

Para o trabalho com a oralidade, falta, entre outras coisas, o que os Parâmetros curriculares nacionais trazem como recepção ativa, ou seja, uma prática que "possibilita o reconhecimento do tipo de linguagem característica, a interpretação crítica das mensagens ou a identificação do papel complementar de elementos não-linguísticos, como a imagem e a trilha sonora, para conferir sentido às mensagens veiculadas" (BRASIL, 1997) através dos vários meios de transmissão usados atualmente e que cada vez mais se popularizam, tais como: TV aberta, TV a cabo, rádio, internet, games diversos, filmes (em cinema, TV ou DVD). Afinal, assim como a escrita lança mão não só do signo verbal (tipo de texto, gênero em que se insere, pontuação, e outras tantas 
marcas gráficas), a oralidade tem como coadjuvante marcadores conversacionais linguísticos e não linguísticos como as pausas, hesitações, alongamentos de vogais e/ou consoantes, repetições, reiterações, ênfases, truncamentos, variedade linguística.

No entanto, antes de mais nada, para fazer um trabalho com oralidade na escola, há que estar claro para o professor, mais do que para o aluno, as concepções que subsidiam a aula no que concerne, principalmente, à: Linguagem, Língua, Oralidade. Esses conceitos guiarão o fazer pedagógico para que o profissional não seja refém de livros didáticos e mesmo de "modismos pedagógicos".

Uma vez que há no país um documento cujo "[...] propósito é apontar metas de qualidade que ajudem o aluno a enfrentar o mundo atual como cidadão participativo, reflexivo e autônomo, conhecedor de seus direitos e deveres" (BRASIL, 1997) e, por outro lado, servir de referencial para o trabalho do educador, "[...] respeitando a sua concepção pedagógica própria e a pluralidade cultural brasileira" (BRASIL, 1997), trazemos aqui os textos dos Parâmetros Curriculares Nacionais. Esses assumem como definição que "a língua é um sistema de signos histórico e social que possibilita ao homem significar o mundo e a realidade". Portanto podemos perceber nessa definição uma tendência da concepção sociocognitiva e interacional de linguagem à qual a linguística textual se filia, pois concebe a língua "como lugar de interação". (KOCH, 2003) E, segundo Koch (2002, p. 1), "[...]a linguística textual é o ramo da linguística que pode dar ao professor de português os subsídios necessários para o desenvolvimento das habilidades mencionadas no documento oficial".

Sobre a linguagem, diz que "é uma forma de ação interindividual orientada por uma finalidade específica; um processo de interlocução que se realiza nas práticas sociais existentes nos diferentes grupos de uma sociedade, nos distintos momentos da sua história". Mais um conceito que se filia à concepção sociocognitiva e interacional de linguagem. O documento ainda orienta que o trabalho com a oralidade seja realizado em sala de aula de forma sistemática e contínua, que deve acontecer no interior de atividades significativas: seminários, dramatização de textos teatrais, simulação de programas de rádio e televisão, de discursos políticos e de outros usos públicos da língua oral. (BRASIL, 1997) Bem de acordo com a definição trazida por Marcuschi, acima transcrita,
(5) Por "modismos pedagógicos" estamos considerando o ato de apropriação de uma terminologia sem o seu devido embasamento teórico, ou seja, quando se abraça uma teoria sem aprofundamento e fazendo-o porque todos a fazem. 
muito embora não haja citação do mesmo no documento em pauta. Além disso, advoga que

[...] o desenvolvimento da capacidade de expressão oral do aluno depende consideravelmente de a escola constituir-se num ambiente que respeite e acolha a vez e a voz, a diferença e a diversidade. Mas, sobretudo, depende de a escola ensinar-lhe os usos da língua adequados a diferentes situações comunicativas. (BRASIL, 1997, p. 38)

Para tanto, o documento lança mão de um termo cunhado dentro da teoria da comunicação que é a "recepção ativa", ou seja, a prática fundamental de análise e reflexão sobre a língua, que tem relação com a produção oral e com a prática de leitura, especialmente no que diz respeito aos textos veiculados pelos meios de comunicação de massa. Nesse caso, precisam ser desenvolvidas habilidades de observar situações de conversação, definida como atividade na qual interagem dois ou mais interlocutores que se alteram constantemente, discorrendo sobre temas próprios do cotidiano; quais sejam: tópicos ou assuntos, tipo de situação, papéis dos participantes, modo e meio do discurso. (FÁVERO, 2003)

O documento nada traz sobre o turno de fala, definido dentro dos estudos de oralidade como a produção de um falante enquanto ele está com a palavra, incluindo a possibilidade de silêncio. E aî está um tópico da oralidade que merece uma especial atenção, pois incide diretamente na formação do falante/ouvinte, cidadão consciente e crítico de sua situação social, política, econômica, uma vez que seja situação sine qua non para a interação comunicativa: é preciso falar, expor suas ideias e argumentar de forma contundente e responsável, mas é também preciso ouvir as argumentações de forma responsável e respeitosa para que a interação verdadeiramente aconteça, na maioria das situações.

É possível que socialmente e/ou no seio da família o educando perceba e aprenda tal comportamento, no entanto, cabe à escola reforçá-lo, uma vez que não haja modelos formais, e sim uma adequação ao contexto situacional. Sendo assim, as regras de

(6) O termo interação responsável é tomado aqui como a ação de saber ouvir, calar, solicitar o turno de fala de forma organizada, dentro do contexto da interação verbal. interação responsável ${ }^{6}$ em sala de aula devem ser aprendidas em contextos significativos em que ficar em silêncio, esperar a vez de falar, solicitar o turno de fala e respeitar a fala do outro tenham 
função e sentido, e não sejam apenas solicitações ou exigências do professor/ da professora. Além disso, é preciso criar um ambiente que convide à escuta atenta e participativa, como, por exemplo, a escuta de músicas, atentando para o som da melodia que interage com a letra da canção e incitando à produção de leitura global do texto.

O trabalho com a oralidade pode ainda e deve ressaltar a contribuição da fala na formação cultural e na preservação de tradições não escritas que persistem mesmo em culturas em que a escrita já entrou de forma decisiva. Nesse caso a oralidade entra como forma de aprendizado de uma dada cultura, considerando a linguagem um constructo social em que o sujeito da linguagem interage social, histórica e ideologicamente com o outro, construindo uma relação dinâmica com a alteridade. E, como diz Bakhtin (apud BRANDÃO, 2001, p. 12) "[...] o texto encena, dramatiza essa relação. Nele, o sujeito divide seu espaço com o outro porque nenhum discurso provém de um sujeito adâmico". Sendo assim, através da língua e da linguagem pode-se compreender um povo, sua história, e essa compreensão leva, via de regra, ao respeito e à compreensão de si mesmo. Afinal, como diz Marcuschi (2001) "Tudo se resume a esse objetivo: ensinar os alunos a perceberem a riqueza que envolve o uso efetivo da língua como um patrimônio maior do qual não podemos abrir mão".

Outro aspecto a se considerar no ensino da oralidade diz respeito à escrita. Embora nas duas o sistema linguístico seja o mesmo para a construção das frases, "[...] as regras de sua efetivação, bem como os meios empregados, são diversos e específicos, o que acaba por evidenciar produtos diferenciados". (MARCUSCHI apud FÁVERO, 2003, p. 9) No entanto, se o trabalho é voltado não para imaginar ou detectar diferenças ou semelhanças e sim estabelecer relações dentro de um contínuo, afastando-se assim um olhar dicotômico sobre essa relação, uma pode ser subsídio para o aprendizado da outra de forma dinâmica e concreta, afinal "[...] entre a fala e a escrita medeiam processos de construção diversos, num continuum tipológico". (MARCUSCHI, 2001, p. 43) É possível, por exemplo, através da retextualização ${ }^{7}$ incentivar o educando a pensar sobre as características próprias da escrita e da fala, traçando um diferencial que elimina traços indesejados de oralidade na escrita e atenta para vícios de fala.
(7) “[...] um processo que envolve operações complexas [de passagem do texto falado para o escrito e vice-versa] que interferem tanto no código como no sentido e evidenciam uma série de aspectos nem sempre bem-compreendidos da relação oralidade-escrita". (MARCUSCHI, 2001, p. 46) 


\section{Sugestões metodológicas}

O aprendizado das operações de retextualização do texto falado para o escrito coloca-se como imprescindível para o melhor domínio da produção escrita que se tem evidenciado muito problemática entre nossos jovens estudantes.

Fávero (2003) sugere o uso de gravadores na sala de aula como um recurso rico em favor da oralidade. Atividades como a gravação da fala do aluno relatando um dos temas estudados em uma das aulas do bimestre e depois levá-lo a retextualizar para a língua escrita, observando as diferenças marcantes em cada uma das modalidades da língua. Ou incentivar a narrativa de uma situação qualquer de seu cotidiano e fazer a transcrição, explicando as operações feitas para chegar ao texto escrito.

Essas são algumas sugestões viáveis, haja vista o baixo custo do aparelho de gravação e a sua disponibilidade através de aparelhos celulares, por exemplo. Muito embora, em regiões de pobreza acentuada e longe dos grandes centros urbanos, o acesso a essas máquinas se torne mais problemático.

Além disso, é possível observar os diálogos televisivos, percebendo ali sotaques regionais, características próprias da fala, variação no grau de formalidade, conforme o programa, seu público alvo e horário de transmissão. E, caso a escola não disponha de aparelho de TV, sempre é possível estipular um programa a ser visto por todos e provocar o debate durante a aula.

Fávero (2003) sugere ainda, um trabalho com crônicas e textos regionalistas, percebendo as marcas da oralidade nesses textos e levantando hipóteses de por que os textos foram escritos dessa forma, qual a intencionalidade presente nessa escolha.

Marcuschi (2001) sugere que se observe a polidez na organização da fala e como esse aspecto interfere de maneira decisiva na qualidade da interação verbal e até mesmo na compreensão e natureza dos atos de fala praticados. Sugere, também, a Identificação dos papéis dos interlocutores e dos diversos gêneros produzidos, determinando suas características.

O documento Parâmetros curriculares nacionais, tanto do ensino fundamental quanto do ensino médio, apresenta algumas sugestões de trabalho nessa área, mas há que se ficar atento, pois percebe-se ali uma tendência à preparação do aluno para falar em público, em situações que não são de fato espontaneamente orais. Situações 
como entrevistas, seminários e debates precisam ser previamente planejadas para serem enunciadas oralmente e costumam ocorrer com mais frequência no próprio ambiente escolar - um caso de "oralização da escrita", segundo Marcuschi (2001, p. 26). Quanto às apresentações teatrais, Marcuschi (2001) e Preti (2004) alertam que não se pode considerá-las como exemplo de texto oral, mas como uma espécie de simulação da fala.

\section{Conclusões}

A escrita sempre teve lugar central na escola por conta de sua grande importância social, ocupando o papel central na interação à distância entre as pessoas, mesmo depois do surgimento do telefone. Porém, o mundo contemporâneo "sofre transformações estruturais significativas" (PRETTO, 1996, p. 32) e, com as distâncias se encurtando cada vez mais e a grande difusão dos aparelhos eletrônicos que facilitam as comunicações - aparelhos celulares, computadores com internet que propiciam mensagens instantâneas, sítios de relacionamentos, sítios de conversação oral e até o barateamento de aparelhos de telefonia fixos - cada vez mais é a oralidade que se torna central em nossa sociedade tão historicamente grafocêntrica. Até em situações em que aparentemente a escrita aparece, ela vem transfigurada de novos códigos (emoticons ${ }^{8}$ ) e com grafia que imita a fala, quase se aproximando da escrita fonética. Mas a escola continua em silêncio no que se refere à oralidade, desconsiderando estas nuances como já o vem fazendo há tempos com a televisão e o que poderia ser uma solução para problemas de interação interpessoal e de leitura, mantémse como um problema.

Pretto (1996), em seu livro cujo título é uma provocação: Uma escola sem/com futuro, educação e multimídia, chama a atenção para a importância da alfabetização para a imagem, uma demanda social a qual a escola não tem dado conta. Esse texto, aproveitando a provocação, chama a atenção para outra demanda social de que a escola não vem dando conta: a alfabetização para o falar/ouvir, binômio que está sempre sendo subjugado pelo escrever/ler. Não se defende aqui a substituição de um pelo outro, mas a equidade para dar conta da demanda social.
(8) Emoticons são recursos eletrônicos de imagens que inicialmente eram enviados ao interlocutor para demonstrar emoções e que atualmente fazem parte das conversações por telefone celular ou via computador e deixam as mensagens tão visuais quanto verbais. 


\title{
The orality in the school: it would be a solution if it was not a problem
}

\begin{abstract}
The present work argues the education of language directed also toward the orality, pointing out this as being practical social interactive that goes beyond the verbal language, also intervening with the interpersonal relations in classroom, privileged scene in this article.

Keywords: Oral communication. Linguistics. Teaching - Methodology. Language and languages.
\end{abstract}

\section{Referências}

BRANDÃO, Helena H. Nagamine. Análise do discurso: leitura e produção textual. In: SANTANA, João Antonio (Org.). Discursos e análises: coletânea de trabalhos. Salvador: UCSAL, 2001.

BRASIL. Secretaria de Educação Fundamental. Parâmetros curriculares nacionais: apresentação dos temas transversais: língua portuguesa. Brasília (DF), 1997.

CAMPINHO, Rosemary Lapa de Oliveira. O silenciamento e o livro didático nas aulas de leitura no ensino médio da rede pública de ensino: um estudo de cunho etnográfico. 2006. 142. Dissertação (Mestrado em Letras e Linguística) - Instituto de Letras, Universidade Federal da Bahia, Salvador, 2007.

FÁVERO, Leonor Lopes; ANDRADE, Maria Lúcia da Cunha Victório de Oliveira; AQUINO, Zilda Gaspar Oliveira de. Oralidade e escrita: perspectivas para o ensino de língua materna. 2. ed. São Paulo: Cortez, 2003.

KOCH, Ingedore Grunfeld Villaça. Desvendando os segredos do texto. 2. ed. São Paulo: Cortez, 2003.

Parâmetros curriculares nacionais, lingüística textual e

ensino de línguas. Revista do Gelne, Fortaleza, v. 4, n. 1, p. 1-12, 2002. Disponível em: < http://www.gelne.ufc.br/revista_ano4_no1_sum. htm >. Acesso em: 28 jul. 2011.

MARCUSCHI, Luiz Antônio. Da fala para a escrita: atividades de retextualização. 3. ed. São Paulo: Cortez, 2001.

MUNIZ, Dinea Maria Sobral. A prática da expressão oral na escola básica. In: ; SOUZA, Emília Helena P. M. de; BELTRÃO, Lícia Maria Freire. Entre textos, língua e ensino. Salvador, BA: EDUFBA, 2007.

PRETI, Dino. Estudos de língua oral e escrita. Rio de Janeiro: Lucerna, 2004.

PRETTO, Nelson De Luca. Uma escola sem/com futuro: educação e multimídia. São Paulo: Papirus, 1996. 
RANGEL, Egon. Tudo na língua é por acaso. In: BAGNO, Marcos. Nada na língua é por acaso: por uma pedagogia da variação linguística. São

Paulo: Parábola, 2007.

Artigo submetido em 04/09/2010 e aceito em 3/04/2011.

R. FACED, Salvador, n.17, p.61-69, jan./jun. 201069 